\title{
Incidence and cause of fractures in European districts
}

\author{
Ronan A Lyons, Eva Sellstrom, Annie M Delahunty, Mitch Loeb, Susanna Varilo
}

Collaboration in Accident Prevention and Injury Control, Welsh Combined Centres for Public Health, University of Wales College of Medicine, Wales, UK R A Lyons

CSL, Midsweden University, Sweden E Sellstrom

Department of Public Health, Iechyd Morgannwg Health, Swansea, Wales A M Delahunty

Sintef, Unimed, Norway

M Loeb

Porvoo Health and Welfare Service, Finland

$S$ Varilo

Correspondence to: Dr R Lyons, West Combined Centre for Public Health, 41 High Street, Swansea SA1 1LT, Wales, UK email:

LYONSRA@cardiff.ac.uk

Accepted 1 March 2000

\begin{abstract}
Aims-To compare fracture rates in European districts.

Setting-Geographically defined areas of Wales (Swansea and Neath Port Talbot), Norway (Harstad, Trondheim, Stavanger, and Drammen), Sweden (Jamtlands), and Finland (Porvoo).

Methods-Surveillance of fractures at emergency departments and hospitals and linkage with population data. Comparison of age adjusted and crude rates. Calculation of confidence intervals for ratios.
\end{abstract}

Results-A total of 4113 fractures occurred in 167560 children during 1996. Fracture rates in south Wales (36 per 1000) were substantially higher than in Scandinavian districts (which were similar). Limiting analysis to the most severe injuries to correct for the possibility of ascertainment bias reduced some of the excess rate in Wales: the Welsh:Scandinavian fracture ratio was 1.82 (95\% confidence interval: 1.64 to 2.03 ).

Conclusions-Fracture rates in Welsh children are substantially higher than in Scandinavian children.

(Arch Dis Child 2000;82:452-455)

Keywords: fractures; incidence; aetiology; international comparison

Non-fatal injures are very common in childhood. Each year about $20-30 \%$ of children in the United Kingdom attend an accident and emergency department as a result of an injury. ${ }^{1-3}$ While there is much published comparing mortality rates from injury in children between countries there is a dearth of information on non-fatal injuries. ${ }^{4-7}$

In 1993, one of us (RAL) started an injury surveillance system in south Wales and noted that attendance rates at accident and emergency departments fell with increasing distance for all injuries with the exception of fractures, indicating that the fracture rate was a good measure of injury morbidity. ${ }^{2}$ Because of concerns about apparently high rates of childhood injuries in south Wales it was decided to compare fracture rates with other districts which were members of the Tipping the balance toward primary care European network. ${ }^{8}$

The objectives of this study were to compare the incidence and causes of fractures in children in participating districts.

\section{Methods}

Districts from four European countries agreed to participate: West Glamorgan in south Wales; four districts in Norway which combine to form the Norwegian Injury Surveillance System; Jamtlands County in Sweden; and Porvoo District in Finland.

The old county of West Glamorgan in south Wales (now City and County of Swansea and Neath Port Talbot County Borough Councils) is a compact, predominately urban area with a fringe of rural hinterland. The furthest distance to travel to a hospital is about $20 \mathrm{~km}$ and all children with fractures are treated at two hospitals. Fractures which occur out of district are followed up in the fracture clinics at the hospitals participating in this study and are included in the results presented here. Further details on the methodology of data collection in this district are available in a separate publication. ${ }^{9}$

The Norwegian National Institute of Public Health registers all those injured attending the emergency departments in Harstad (northern Norway), Trondheim (central west coast), Stavanger (south west coast), and Drammen (east coast) districts. In each district, inpatient and outpatient data are collected from the hospital as well as local emergency clinics. No other facilities in these areas treat serious injuries so that all fractures should be recorded. The data collection methodologies used by the Norwegian districts were copied by the other districts and are described elsewhere. ${ }^{9}$

Jamtslands County is a large, predominantly rural area in the middle of Sweden centred around the town of Ostersund. All children with fractures are treated at the central hospital in Ostersund. Data were collected, using the standardised format on all incident cases attending the emergency department at the hospital.

Porvoo is a municipality on the south coast of Finland, about $50 \mathrm{~km}$ to the east of Helsinki. It is a mixed rural and urban area with health facilities centred in the town of Porvoo. Childhood fractures are treated at the health centre and hospital in Porvoo. Data were collected on all incident cases using the standardised format.

Participants agreed to collect data at all hospitals and clinics treating childhood fractures in their district during the calendar year 1996 . Data were collected on incident cases in children aged $0-14$ years, including age, sex, location, and activity at time of incident, and anatomical diagnoses using a pre-agreed format based on the Norwegian Injury Surveillance System and NOMESCO coding. ${ }^{10}{ }^{11}$ 
Table 1 Number and standardised fracture rate by site and district

\begin{tabular}{|c|c|c|c|c|c|c|c|c|}
\hline & \multicolumn{2}{|c|}{ S. Wales } & \multicolumn{2}{|c|}{ Porvoo } & \multicolumn{2}{|c|}{ Famtlands } & \multicolumn{2}{|c|}{ Norwegian } \\
\hline & No. & Rate/1000 & No. & Rate/1000 & No. & Rate/1000 & No. & Rate/1000 \\
\hline Skull & 49 & 0.73 & 1 & 0.10 & 1 & 0.04 & 14 & 0.21 \\
\hline Face/nose & 77 & 1.12 & 9 & 0.84 & 6 & 0.23 & 40 & 0.62 \\
\hline Vertebra & 2 & 0.03 & 0 & 0.00 & 4 & 0.16 & 3 & 0.05 \\
\hline Scapula & 5 & 0.07 & 0 & 0.00 & 0 & 0.00 & 18 & 0.28 \\
\hline Ribs/sternui & 6 & 0.08 & 0 & 0.00 & 0 & 0.00 & 18 & 0.28 \\
\hline Clavicle & 152 & 2.22 & 19 & 1.87 & 35 & 1.40 & 102 & 1.58 \\
\hline Humerus & 175 & 2.56 & 20 & 1.82 & 36 & 1.44 & 55 & 0.87 \\
\hline Radius/ulna & 888 & 12.89 & 52 & 4.74 & 129 & 5.09 & 131 & 2.09 \\
\hline Carpal & 132 & 1.87 & 0 & 0.00 & 8 & 0.31 & 268 & 4.27 \\
\hline Metacarpa & 195 & 2.70 & 4 & 0.37 & 18 & 0.70 & 63 & 0.98 \\
\hline Fingers & 351 & 5.04 & 38 & 3.46 & 52 & 2.06 & 108 & 1.7 \\
\hline Pelvis & 7 & 0.10 & 1 & 0.09 & 1 & 0.04 & 2 & 0.03 \\
\hline Femur & 22 & 0.31 & 3 & 0.28 & 7 & 0.29 & 18 & 0.28 \\
\hline Patella & 6 & 0.08 & 0 & 0.00 & 1 & 0.04 & 9 & 0.14 \\
\hline $\mathrm{Tib} / \mathrm{fib}$ & 160 & 2.31 & 22 & 2.05 & 52 & 2.10 & 63 & 0.98 \\
\hline Tars/meta & 119 & 1.72 & 1 & 0.10 & 23 & 0.92 & 87 & 1.38 \\
\hline Toes & 101 & 1.43 & 20 & 1.84 & 12 & 0.48 & 54 & 0.87 \\
\hline Multiple & 16 & 0.23 & 0 & 0.00 & 0 & 0.00 & 22 & 0.34 \\
\hline Total & 2463 & 35.50 & 190 & 17.56 & 285 & 15.27 & 1075 & 16.95 \\
\hline Crude rate $(95 \% \mathrm{CI})$ & \multicolumn{2}{|c|}{$36.09(34.7-37.5)$} & \multicolumn{2}{|c|}{$17.75(15.2-20.3)$} & \multicolumn{2}{|c|}{$15.47(13.9-17.0)$} & \multicolumn{2}{|c|}{$16.86(15.9-17.9)$} \\
\hline Pop $0-14 y$ & \multicolumn{2}{|c|}{68231} & \multicolumn{2}{|c|}{10704} & \multicolumn{2}{|c|}{24874} & \multicolumn{2}{|c|}{63751} \\
\hline
\end{tabular}

Aggregated anonymised data were sent to south Wales for analysis. Statistical comparison involved calculation of crude and age standardised fracture rates and the plotting of time series graphs to look at seasonal variation by selected causes. Age standardisation was carried out in 5 year age bands $(0-4,5-9,10-14)$ with a $36: 32: 32$ ratio reflecting the distribution of this age group in the standard European population used by the World Health Organisation. ${ }^{12}$

\section{Results}

The population (aged $0-14$ years) of the districts ranged from 10704 in the smallest (Porvoo) to 68231 in the largest (south Wales), and the total number of fractures recorded varied from 190 (Porvoo) to 2463

Table 2 Fracture rates per 1000 children by district for all and selected causes

\begin{tabular}{lcccc}
\hline Cause & South Wales & Porvoo & Famtlands & \multirow{2}{*}{ Norwegian } \\
\hline All & $36.1(2463)$ & $17.75(190)$ & $15.37(385)$ & $17.18(1077)$ \\
Sports and leisure & $12.68(865)$ & $4.39(47)$ & $6.71(167)$ & $5.31(337)$ \\
$\quad$ Ball sports & $5.38(367)$ & $1.40(15)$ & $1.32(33)$ & $2.31(147)$ \\
Soccer & $2.89(197)$ & $1.03(11)$ & $0.56(15)$ & $1.28(81)$ \\
Winter sports & $0.43(29)$ & $1.31(14)$ & $2.53(63)$ & $1.10(70)$ \\
Skating & $1.64(112)$ & $0.09(1)$ & $0.16(4)$ & $0.18(12)$ \\
Gymnastics & $0.59(40)$ & $0.09(1)$ & $0.36(9)$ & $0.33(21)$ \\
Combat sports & $0.44(30)$ & $0.09(1)$ & $0.04(1)$ & $0.05(3)$ \\
Horse riding & $0.37(25)$ & $0.19(2)$ & $0.68(17)$ & $0.13(8)$ \\
Cycling & $2.72(189)$ & $1.87(20)$ & $1.26(30)$ & $0.99(63)$ \\
Motor vehicle accidents & $0.51(35)$ & $0.47(5)$ & $0.16(4)$ & $0.02(1)$ \\
\hline
\end{tabular}

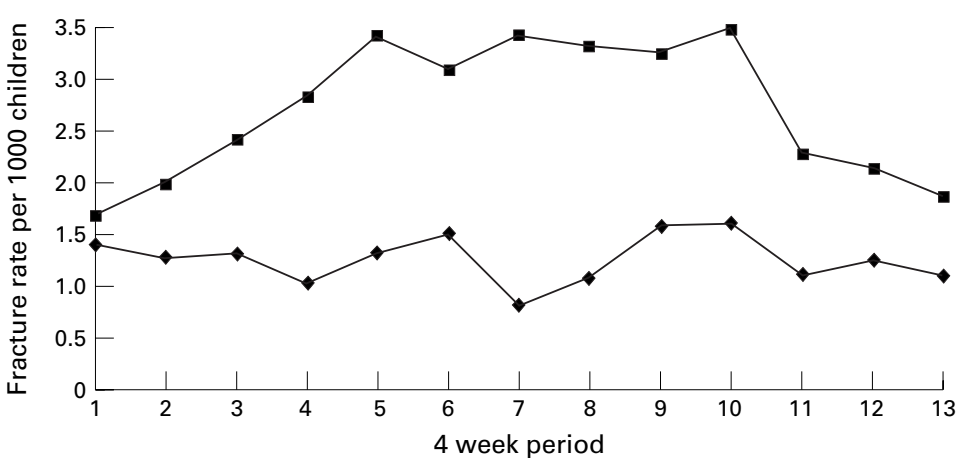

Scandinavian districts $\rightarrow-$ South Wales

Figure 1 Distribution of fracture rates by four week period and area: all fractures. (south Wales). Altogether 4113 fractures occurred in 167560 children during the year. When children with more than one fracture $(1.9 \%)$ are counted only once, the results are very similar.

Table 1 shows the number and age standardised fracture rate by anatomical site and the overall rate for each district. Confidence intervals were calculated for the crude non-age adjusted rates as these were similar to the standardised rates. Fracture rates in south Wales were considerably higher than the three north European districts, which had very similar rates. If south Wales had the same fracture rate as the combined Scandinavian districts the expected number of fractures would be 1131 compared with the observed number of 2463. This yields a ratio of 2.17 (95\% confidence interval (CI): 2.09 to 2.26 ). Fractures at most anatomical sites were more common in south Wales, particularly fractures of the radius and ulna. It is always possible that some fractures may not come to medical attention and this would be more likely to occur for minor fractures in areas furthest from hospitals. In order to evaluate the potential for ascertainment bias, we performed a sensitivity analysis, limiting the analysis to fractures which would almost certainly result in hospital treatment everywhere. These were fractures of the vertebral column, humerus, pelvis, femur, patella, and tibia and fibula. We excluded skull fractures as not all might be recognised, and fractures of the radius and ulna as not all greenstick fractures might be identified. Similarly we excluded fractures of the digits, hands and feet, and facial fractures (mainly noses). In this group there were 372 fractures in south Wales compared with an expected 204 (based on rates from the Scandinavian districts combined) which yield a ratio of 1.82 (95\% CI: 1.64 to 2.02 ).

Table 2 shows the incidence of fractures per thousand children by all and selected causes. About one third (32\%) of all fractures resulted from sporting and leisure activities, $1.4 \%$ from motor vehicle accidents, and the remainder from general activities resulting from slips, 


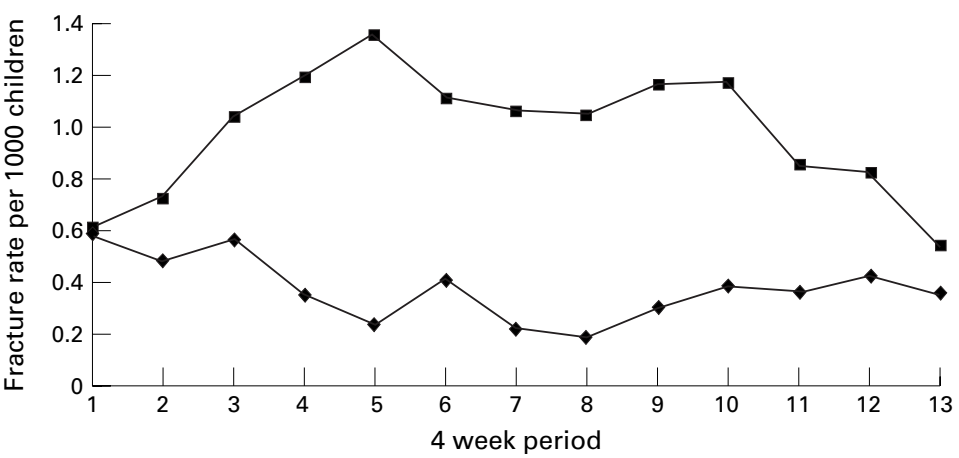

$\longrightarrow$ Scandinavian districts $\rightarrow-$ South Wales

Figure 2 Distribution of fracture rates by four week period and area: all sports and leisure related fractures.

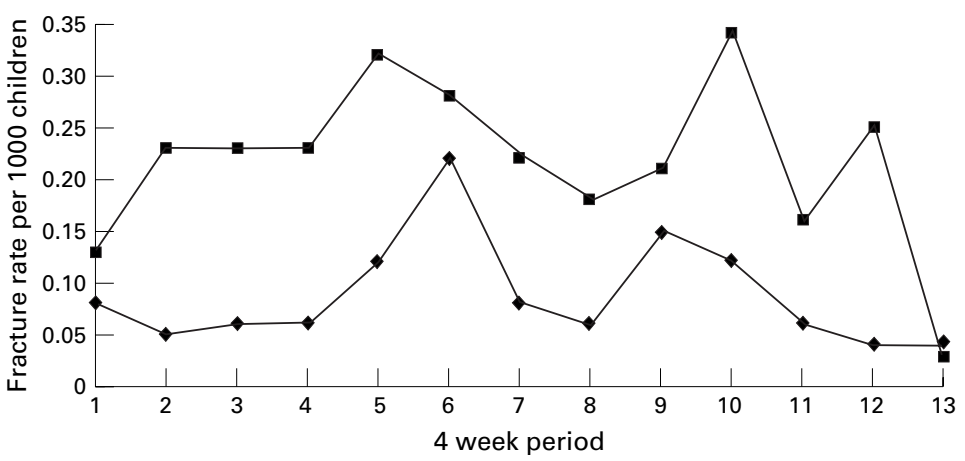

$\multimap$ Scandinavian districts $\rightarrow-$ South Wales

Figure 3 Distribution of fracture rates by four week period and area: soccer related fractures.

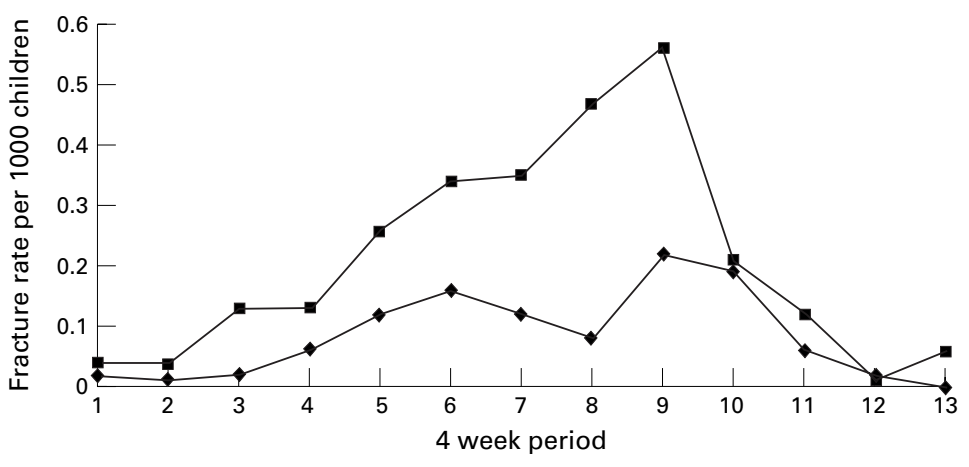

$\multimap$ Scandinavian districts $\rightarrow-$ South Wales

Figure 4 Distribution of fracture rates by four week period and area: cycling related fractures.

trips, and falls. Rates of sports and leisure fractures are particularly high in south Wales with ball sports being two to four times as common as other districts. We explained this by a higher rate of soccer related fractures, and rugby $(n=132)$ which is not played in other districts. The rate of skating related fractures is also substantially higher in south Wales which is a result of the popularity of in-line skating.

In order to elucidate further the reason for higher rates of fractures in south Wales, the year was divided into thirteen four-week periods and the incidence of fractures graphically illustrated.

Figure 1 shows the distribution of all fractures by four week period for each district; fig 2, the distribution of all sports and leisure related fractures; fig 3, the distribution of soccer related fractures; and fig 4 the distribution of cycling related fractures.

The incidence of all fractures shows a steady rise from winter to summer in south Wales which is not apparent in other district. Sports related fractures increase in summer in south Wales and tend to decrease in other districts. Soccer related fractures peak in April/May and again in September. Cycling related fractures increased in incidence from winter to peak in the mid July and August period. Winter sports related fractures show the expected seasonal distribution in the Scandinavian countries (data not shown).

\section{Discussion}

This study shows that fracture rates in children vary across Europe, with substantially higher rates in south Wales than in the Scandinavian countries. As far as we can ascertain it is the first comparative study of children's fractures across districts from different European countries. A small number of studies have reported on the incidence of childhood fractures in defined populations in single districts using different time periods. ${ }^{10} 1314$

Kopjar and Wickizer recently published a population based study of fractures in children aged $0-12$ years from Rogaland County in Norway, occurring during 1992-1995, which revealed an annual fracture incidence of 12.8 per 1000 children. ${ }^{10}$ Given the effect of the different age groups this is very similar to the rate of 15.6 per 1000 for the Norwegian district in 1996. A study of fractures in the Malmö district of Sweden reported an annual incidence of 21.1 per 100 in children aged $0-16$ years in the $1970 \mathrm{~s}^{13}$ This result is similar to the rates of 17.6 per 1000 in the Swedish district in this study, given that fracture rates in 15 and 16 year olds are substantially higher than the average for 0-14 year olds.

A study of fractures in children aged 0-12 years from Nottingham, England during the first six months of 1981 reported an estimated annual fracture rate of 16 per $1000 .{ }^{14}$ The south Wales district with a fracture rate of 35.5 per 1000 is the nearest district to compare with Nottingham. As fracture rates in 13 and 14 year olds are substantially higher than the average rate for $0-12$ year olds, some difference would be expected. However, the magnitude of the difference means that this can only account for a small proportion of the difference.

Unfortunately historical data from south Wales and contemporary data from Nottingham are not available to determine whether the difference is a result of any increasing trend in fractures or systematic differences between areas. Landin reported a fivefold increase in fracture rates caused by sports between 1950 and 1979 in Sweden, but more recent or extensive data are not available to confirm this hypothesis. ${ }^{13}$

Before accepting the results of this study it is important to consider alternative explanations. The data rely on all incident fractures being recorded in the participating hospitals and 
clinics. In the participating districts all fracture treatment centres were included. It is possible that a small number of fractures occurring around the boundaries of a district could have been treated elsewhere, but this is unlikely to account for more than a tiny proportion and could not account for the two- to threefold difference we reported.

In each of the districts the hospitals and treatment centres are located in the most populated areas, where the majority of residents are to be found, and even if there was a decline in attendance for more minor fractures with increasing distance, this would not account for the size of the difference reported. The rate of all fractures in the south Wales population is 2.17 times that of the average of the Scandinavian districts (95\% CI: 2.09 to $2.26)$. When only severe fractures are included (which are unlikely to be missed) the rate in south Wales is still 1.82 times that of the Scandinavian districts (95\% CI: 1.64 to 2.03). Ascertainment bias can only explain a proportion of the difference and most reflects differences in actual incidence.

Because of small numbers in some of the districts the results from south Wales and the Norwegian districts will be most stable and easier to compare, as these are based on the largest populations. We were interested to note that the fracture incidence in the Norwegian districts in this study is very similar to published statistics from another Norwegian district for the 1992-95 years, a factor which would tend to increase confidence in the results. ${ }^{10}$

In order to try to understand the reasons for higher fracture rates in south Wales children, we analysed data on preceding activities. Most fractures in every district were caused by slips, trips, and falls in activities such as walking, running, climbing, and general playing with other children. The majority of the remainder resulted from sporting and specific leisure activities as shown in table 2 . The excess of ball sports associated fractures in south Wales is a result of higher rates of soccer related fractures in this district and also to rugby injuries, a sport which is not played in the other districts.

Unfortunately we do not have data on frequency of playing or time at risk for each activity to determine whether the higher rates of fracture are a result of higher rates of participation or higher risk per unit of activity.

In order to get some indication of the distribution of risk during the year, the number of fractures in each four week period was calculated and graphically represented. Figure 1 shows that the rate appears to be reasonably constant throughout the year in the Scandinavian districts but in south Wales the rate of fractures in the middle of the year is approximately twice that in the winter period. The likely explanation is climatic. In Scandinavia, where ice and snow are common in winter, activity levels in children may not decline as much as in south Wales where the climate tends to be damp, wet, and unenticing.

Once spring arrives and the temperature and weather and amount of daylight improves, childhood activity increases and with it the risk of injury. This is clearly the case as shown in fig 2 for all sporting activities. The higher risk associated with winter sports in Scandinavia outweighs the risk associated with summer sports such as soccer. In all areas the rate of soccer related fractures rose in spring, fell in mid summer in the school holidays, rose again in autumn, and declined in winter (data not shown). The higher early spring rate in south Wales probably reflects the fact that it is possible to play soccer for a greater part of the year in a milder climate.

The results of this study are mirrored by the findings of a 1994 World Health Organisation survey of 11-15 year old children from 22 countries. ${ }^{7}$ This study reported that $17.4 \%$ of Welsh children aged 11-15 required medical treatment for an injury during the year compared with rates of $8.9 \%$ in Norway, $8.3 \%$ in Finland, and $6.8 \%$ in Sweden.

These findings support the hypothesis that the high rates of fractures in Welsh children are real and not artefactual. Further research is required to elucidate the reasons behind the high fracture rate associated with certain sporting activities and to implement effective intervention strategies.

1 Sibert JR, Maddocks GB, Brown BM. Childhood accidents - an endemic of epidemic proportions. Arch Dis Child 1981;56:225-34.

2 Lyons RA, Lo SV, Heaven M, Littlepage BNC. Injury Lyons RA, Lo SV, Heaven M, Littlepage BNC. Injury
surveillance in children-usefulness of a centralised surveillance in children-usefulness of a centralised
database of accident and emergency attendances. Injury database of accident and
Prevention 1995;1:173-6.

3 Walsh SSM, Jarvis SN, Towner EML, Aynsley-Green A. Annual incidence of unintentional injury among 54000 children. Injury Prevention 1996;2:16-20.

4 Anon. Mortality Statistics in the EU. Eurorisc Newsletter 1997;1:2-3.

5 WHO. World health statistics annual, 1996. Geneva: World Health Organisation, 1998.

6 Jarvis S, Towner E, Walsh S. Accidents. In: The health of our children-decennial supplement, series DS No.11. London: HMSO, 1995.

7 WHO. Gender and health in adolescence. Copenhagen: World Health Organisation, 1999.

8 Anon. Tipping the balance towards primary health care: a Anon. Tipping the balance towards primary health care: a
research project of the European communities. European research project of the European comm
fournal of Public Health 1992;2:131-219.

9 Lyons RA, Delahunty AM, Kraus D, et al. Children's Lyons RA, Delahunty AM, Kraus D, et al. Children's
fractures: a population based study. Injury Prevention 1999; fractures: a

10 Kopjar B, Wickizer TM. Fractures among children: incidence and impact on daily activities. Injuries Prevention 1998;4:194-7.

11 NOMESCO. Nordic Medico-Statistical Committee. Classification for accident monitoring, 2nd revised edition. Copenhagen: Nordic Medico-Statistical Committee, 1990.

12 Waterhouse J, Correa P, Muir C, Powell J. International Agency for research into cancer. Cancer incidence in five continents, Volume III. Lyon: IARC, 1976:456.

13 Landin LA. Fracture patterns in children. Acta Orthop Scand 1983;54(suppl 202):1-95.

14 Worlock P, Stower M. Fracture patterns in Nottingham children. F Pediatr Orthop 1986;6:656-60. 